\title{
UN NUEVO SAN DIEGO DE ALCALÁ ATRIBUIDO A JUAN MARTÍNEZ MONTAÑÉS
}

\author{
JOSÉ MANUEL MORENO ARANA \\ ANTONIO ROMERO DORADO \\ Universidad de Sevilla
}

\begin{abstract}
Resumen
Este estudio da a conocer una nueva imagen escultórica de San Diego de Alcalá, atribuyéndola a Juan Martínez Montañés y datándola, en base a varias evidencias, en torno a 1590-1591, por lo que podría ser una de las primeras obras conservadas del artista. La obra se localiza en Sanlúcar de Barrameda, en la antigua Iglesia del Convento de San Francisco. Asimismo, se relaciona la nueva escultura con otras obras de la misma iconografía vinculadas a dicho autor.
\end{abstract}

\section{Palabras clave}

Juan Martínez Montañés, San Diego de Alcalá, escultura, escuela sevillana, Sanlúcar de Barrameda

\section{A NEW SAINT DIDACUS OF ALCALÁ ATTRIBUTED TO JUAN MARTÍNEZ MONTAÑÉS}

\begin{abstract}
This paper presents a new sculpture of Saint Didacus of Alcalá preserved in Sanlúcar de Barrameda, at the Church of the Convent of Saint Francis, which is attributed here for the first time to Juan Martínez Montañés. The new work is analyzed in comparison with other works of the same iconography related to the aforementioned artist. In addition, based on various evidences, a chronology around 1590-1591 is proposed, which makes this new sculpture one of the artist's earliest preserved works.
\end{abstract}

$$
\text { Key words }
$$

Juan Martínez Montañés, Saint Didacus of Alcalá, sculpture, Sevillian school, Sanlúcar de Barrameda. 

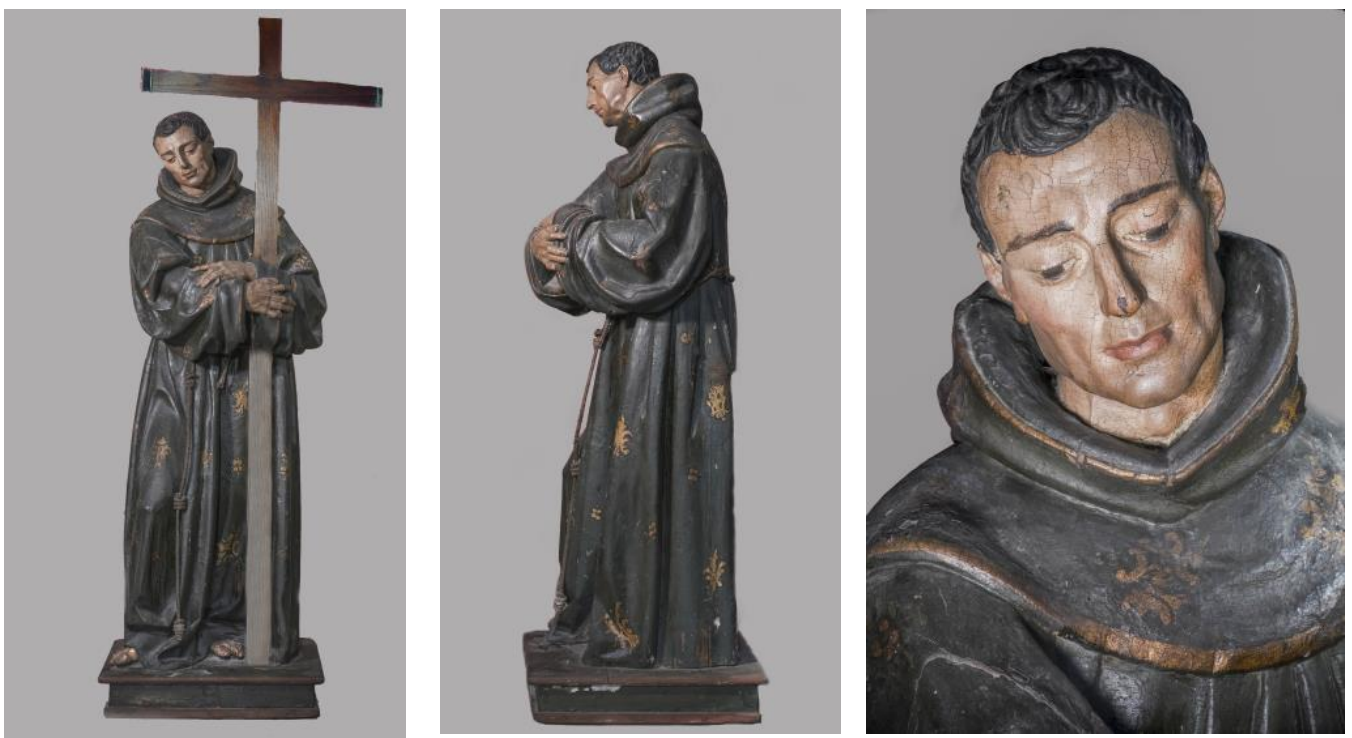

Figs. 1, 2 y 3. San Diego de Alcalá, Iglesia de San Francisco, Sanlúcar de Barrameda, aquí atribuido a Juan Martínez Montañés, hacia 1590-1591. Montaje fotográfico portando la Cruz. Autor de la fotografía: Óscar Franco Cotán.

La exposición dedicada a Juan Martínez Montañés, recientemente organizada por el Museo de Bellas Artes de Sevilla, nos ha dado la oportunidad de disfrutar, como nunca antes, de la obra del ilustre escultor alcalaíno ${ }^{1}$. Además, nos ha permitido recorrer parte de su producción, a través de un sencillo discurso museológico, organizado -en gran medida-, según la iconografía de las esculturas expuestas. En este sentido, y con la intención de ahondar en el conocimiento de su imperecedera obra, en este estudio damos a conocer una nueva escultura que atribuimos a Montañés.

La pieza que presentamos es una imagen de San Diego de Alcalá que se conserva en la Iglesia de San Francisco de Sanlúcar de Barrameda (figs. 1-3)². En concreto, se sitúa en una hornacina abierta en un muro de la zona del transepto del templo, en el lado de la epístola. Es una escultura de $1,62 \mathrm{~m}$. de altura ${ }^{3}$, tallada en pino. El santo, vestido con hábito franciscano, se representa de pie, con un claro contrapposto. La pierna derecha se adelanta de modo que la gruesa tela deja entrever su anatomía. La izquierda, por su parte, queda retrasada creándose una profunda oquedad que, sin embargo, no termina de ocultar el volumen y la disposición de esta pierna. Finalmente, el hábito cae holgadamente sobre los pies y la propia peana. Aunque en la actualidad la ha perdido, el santo abraza la cruz con una actitud de recogimiento e introspección que se acentúa con la mirada baja y la inclinación de la cabeza hacia delante y hacia su derecha.

La altura donde se encuentra la obra, su precaria conservación y un acabado polícromo moderno y deficiente, no han favorecido su correcta percepción. No obstante, al ser examinada de cerca, presenta un indudable interés y su análisis nos hace vincularla a la gubia de Juan Martínez Montañés, como veremos.

En 1588, tras la canonización de San Diego, la orden franciscana se apresuró a crear imágenes para representarlo. Así, varios conventos del antiguo Reino de Sevilla pusieron sus ojos en Montañés, un prometedor joven que ese mismo año había obtenido el título de maestro escultor en Sevilla, donde empezaba a dar los primeros pasos de una carrera profesional independiente. De hecho, la aceptación que pronto alcanzó -debido a sus

\footnotetext{
${ }^{1}$ Varios autores, 2019a: 1-292.

${ }^{2}$ Queremos mostrar nuestro agradecimiento a D. Óscar Franco Cotán y D. Raúl Jiménez Santos por la ayuda recibida para estudiar esta obra. Al primero de ellos le debemos todas las fotografías contenidas en este artículo, a excepción de las figuras 9 y 11, realizadas por D. José Morón Borrego.

${ }^{3}$ Esta altura incluye la peana, que mide $11 \mathrm{~cm}$ de alto.
} 
extraordinarias dotes artísticas-, explicaría los sucesivos encargos de imágenes de San Diego que el artista recibió desde Cádiz, Ayamonte y la propia Sevilla ${ }^{4}$. Por ello, podemos afirmar que Montañés tuvo un papel decisivo en la creación del modelo iconográfico de San Diego de Alcalá.

Parece que fue en torno a 1589 cuando se le encargó la que se supone que podría ser la primera de estas representaciones, con destino al Convento de San Francisco de Cádiz. Se trata de una obra problemática debido a su probable existencia efímera, pues parece que pudo destruirse durante la Toma de Cádiz de $1596^{5}$. No obstante, algunos autores la han identificado con la imagen de candelero del santo que se encuentra en la sacristía de este convento ${ }^{6}$. Por nuestra parte, debemos decir que, aunque la actual pieza es de gran interés, su acentuada y extática expresividad, así como la técnica del cabello, nos llevan a una estética más avanzada y barroca que la que caracteriza a Montañés, mostrando además rasgos físicos no asimilables al estilo del alcalaíno.

Sí se conserva, aunque muy alterada por intervenciones posteriores, la imagen del santo que realizó en 1590 para el convento de Ayamonte, actualmente conservada en la Parroquia de Nuestra Señora de las Angustias (figs. 4 y 5). En su contrato se estableció como modelo la imagen gaditana, lo que prueba el éxito alcanzado con la misma ${ }^{7}$. Desgraciadamente, la escultura ayamontina, de talla completa y tamaño algo inferior al natural, fue destrozada en 1936, por lo que hay que ser prudentes a la hora de valorar su actual aspecto, en parte rehecho. En todo caso, suponemos que, al menos, la composición general de la escultura y la mayor parte de sus rasgos físicos debieron de conservarse. De este modo, se presenta al santo abrazando la cruz y en una disposición frontal animada por el equilibrado movimiento de cabeza, manos y piernas, en suave contrapposto. El rostro es maduro y de expresión grave e introvertida.

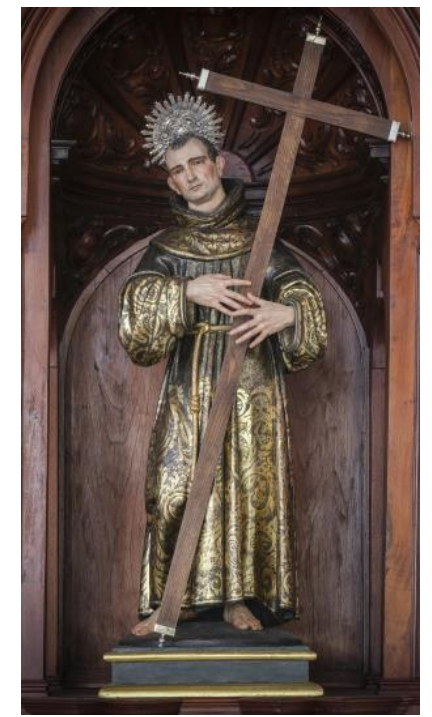

Fig. 4. San Diego de Alcalá, Parroquial de Nuestra Señora de las Angustias, Ayamonte, Juan Martínez Montañés, 1590. Intervenida tras ser destruida en 1936. Autor de la fotografía: Óscar Franco Cotán.

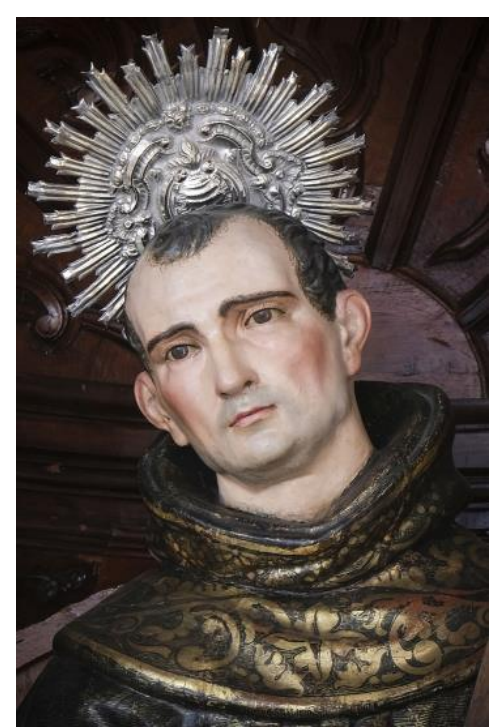

Fig.5. Pormenor del rostro San Diego de Alcalá (detalle), Parroquia de Nuestra Señora de las Angustias, Ayamonte, Juan Martínez Montañés, 1590. Intervenida tras ser destruida en 1936. Autor de la fotografía: Óscar Franco

\footnotetext{
${ }^{4}$ Debemos recordar además que era habitual que las órdenes religiosas contaran con un mismo artista para los encargos de los cenobios de áreas geográficas cercanas.

5 Así se defiende en: Sancho, 1949, 297-298. Pemán, 1982: 21.

${ }^{6}$ Hernández, 1962: 451-452.

${ }^{7}$ Hernández, 1939: 47.
} 
$\mathrm{Al}$ año siguiente, en 1591 Montañés concertó con el médico Juan Sánchez una nueva imagen que se veneró en el Convento de San Diego de Sevilla ${ }^{8}$. Esta se ha identificado con la que hoy se halla en el retablo mayor de la Iglesia de San Buenaventura de la misma ciudad (fig. 6), que sin embargo muestra también un aspecto renovado, aparentemente en el siglo $\mathrm{XX}$. Sigue muy de cerca a la de Ayamonte, siendo los rostros bastante cercanos en sus rasgos y en su mirada frontal e idéntica la postura de las manos portando la cruz. En cualquier caso, se invierte el movimiento de la cabeza y de la pierna que queda adelantada. En el caso de que aceptemos que esta fue la imagen contratada en 1591, algo que no nos parece descabellado, debemos decir que posee un aspecto menos refinado que la de Ayamonte, quizás fruto de una desafortunada intervención o bien debido a la importante participación del taller.

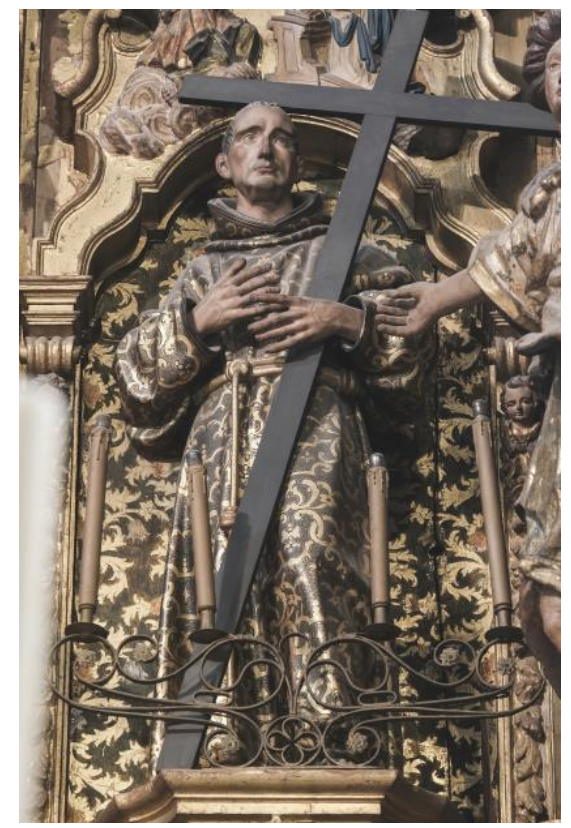

Fig. 6. San Diego de Alcalá, Iglesia de San Buenaventura, Sevilla, Juan Martínez Montañés, 1591. Posiblemente intervenida en el siglo XX. Autor de la fotografía: Óscar Franco Cotán.

Además de las imágenes de San Diego realizadas para Cádiz, Ayamonte y Sevilla, es interesante comprobar cómo en otros conventos franciscanos del Reino de Sevilla, se experimentó el mismo proceso de realización de nuevas tallas en los años siguientes a la canonización ${ }^{9}$. Nos referimos a Jerez y Vejer de la Frontera, así como a El Puerto de Santa María. En ellos se contó con un artista mucho más modesto que Montañés, como fue el escultor holandés Hernando Lamberto, vecino de Jerez, que alcanzó una gran actividad en el entorno de esa ciudad a finales del siglo XVI y primeros del XVII. En este sentido, nos consta el encargo a Lamberto de esculturas del santo con destino a los conventos de Vejer de la Frontera, en 1592, y El Puerto de Santa María, en $1593^{10}$. Ambas han desaparecido pero sus respectivos contratos nos informan de que se hicieron tomando como modelo la imagen que se veneraba en el convento jerezano. Esta última pieza sí parece perdurar, ya que se encuentra dentro de él en el mismo lugar donde sabemos que tuvo su altar, la capilla de la Concepción o del Voto (fig. 7). Hoy ocupa la hornacina del ático del retablo dieciochesco que preside este espacio. La escultura, que muestra el estilo del propio Lamberto, fue titular

\footnotetext{
${ }^{8}$ López, 1932: 229. Hernández, 1949: 31.

${ }_{9}^{9}$ Merece también citarse aquí la imagen de San Diego de la iglesia de San Francisco de Tunja (Colombia), pieza de origen sevillano que posee ciertas afinidades formales con la escultura sanluqueña, en especial en el plegado del hábito. Ha sido identificada con la que se envía desde Sevilla en 1592 con destino a este convento franciscano colombiano. Obra de desconocida autoría, ha sido relacionada con algún seguidor de Jerónimo Hernández en: Gila/Herrera, 2010: 508-510. También ha sido estudiada en: Contreras, 2019: 44-45.

${ }^{10}$ Jácome/Portillo, 2003: 53-54.
} 
de una cofradía que se fundó el 12 de octubre de 1591 por el gremio de los sastres ${ }^{11}$. Pero lo verdaderamente interesante para nuestro estudio es que, dentro de la discreta calidad que suele caracterizar al artista holandés, esta obra sigue muy de cerca la composición del San Diego sanluqueño. Así se comprueba en los brazos entrelazados, el movimiento e inclinación de la cabeza, la marcada flexión de la pierna derecha, y en torno a ella, la distribución general de los pliegues del hábito. Estas características, tan similares al San Diego sanluqueño, pensamos que nos indican que Lamberto -de limitadas dotes técnicas y creativas- se basó en el modelo montañesino que vemos en la imagen de Sanlúcar. Una segunda copia conservada de la obra que presentamos se encuentra en el mismo templo que alberga el original, en la calle lateral izquierda del retablo de la capilla de San Antonio de Padua (fig. 8). Se trata de una pieza de pequeño formato que, aunque esté repolicromada y ubicada en un retablo del siglo XVIII, muestra el estilo del mismo Lamberto y pudo haberse realizado en origen para la clausura del monasterio. En cualquier caso, la existencia de ambas réplicas nos indica el éxito alcanzado por el original en la zona.

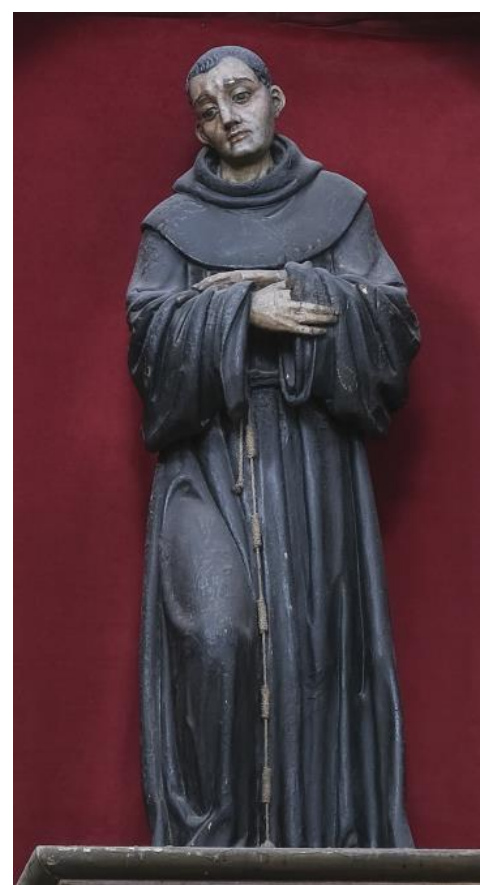

Fig. 7. San Diego de Alcalá, Iglesia de San Francisco, Jerez de la Frontera, atribuido a Hernando Lamberto, hacia 1591-1592. Autor de la fotografía: Óscar Franco Cotán.

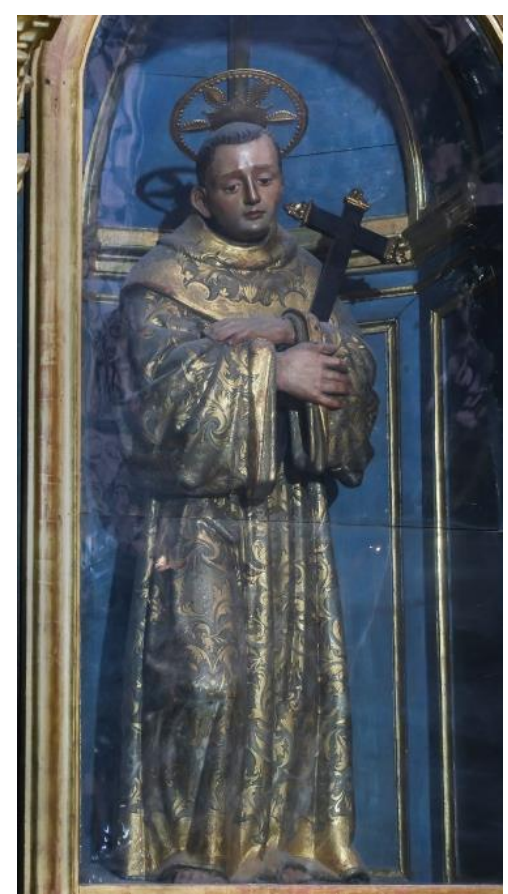

Fig. 8. San Diego de Alcalá, Iglesia de San Francisco,Sanlúcar de Barrameda, atribuido a Hernando Lamberto, después de 1591. Autor de la fotografía: Óscar Franco Cotán.

Para fundamentar la atribución a Montañés del San Diego de Sanlúcar, pasemos ahora a realizar un análisis comparativo, que apunte a otras creaciones del maestro que tienen rasgos en común con la nueva obra. Respecto a la talla de Ayamonte y, sobre todo, a la de Sevilla, la imagen sanluqueña -pese a su mal estado y la pésima calidad de su actual policromía-, muestra mayor sutileza compositiva, así como mejor resolución y plasticidad en el modelado. Llamativo, por ejemplo, es el tratamiento del hábito, que cae holgadamente sobre los pies y la propia peana, mediante un profundo y pesado plegado, muy semejante al que empleó en el San Francisco de Asís para el Convento de Santa Clara de Sevilla, hacia 1623-1625 (fig.

${ }^{11}$ Mesa, 1888: 497. 
9) ${ }^{12}$. Asimismo, la pierna que queda retrasada crea una característica oquedad en la tela, que está presente en otras muchas esculturas del artista.

Junto al modelado del hábito franciscano, también nos parece muy elocuente el gesto de los brazos entrelazados. Para este detalle hay que remitir a los relieves del Bautismo de Cristo para el Convento de la Concepción de Lima (1608-1622), ahora en la Catedral de la ciudad peruana, y para el del Socorro de Sevilla (1620-1622), hoy en la Iglesia de la Anunciación (fig. 10). En ellos Cristo cruza sus brazos de manera muy semejante a nuestro San Diego. En este último las manos se muestran más próximas entre sí pero la gesticulación de los dedos es la misma. En este sentido, tenemos que advertir que se ha dicho que el antecedente para los relieves montañesinos, y en concreto para la postura de Jesús, se encuentra en el que sobre el mismo tema hizo Gaspar Núñez Delgado entre 1605-1606 para el convento hispalense de San Clemente, a su vez inspirado de una manera muy libre en una estampa de 1575 sobre composición de Francisco Salviati abierta por Cornelis Cort ${ }^{13}$. No obstante, atendiendo a la cronología hipotéticamente anterior del San Diego de Sanlúcar que vamos a proponer en este artículo, la talla sanluqueña podría considerarse también un precedente compositivo para los referidos relieves.

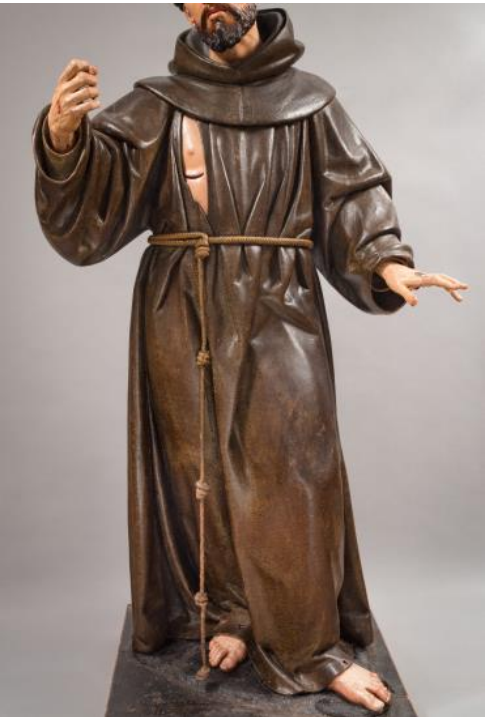

Fig. 9. San Francisco de Asís (detalle), Iglesia de Santa Clara, Sevilla, Juan Martínez Montañés, 16231625.

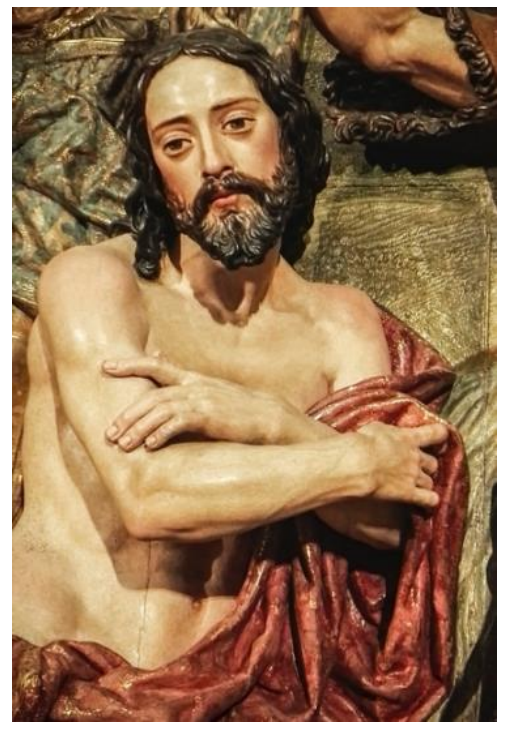

Fig. 10. Bautismo de Cristo (detalle), Iglesia de la Anunciación, Sevilla, Juan Martínez Montañés, 1620-1622. Autor de la fotografía: Óscar Franco Cotán.

En la línea de Montañés está también, pese al deterioro y a la tosca capa pictórica actual, la morfología de los pies y la silueta sinuosa de la base o suelo sobre el que se apoya la escultura, que aparece levemente resaltada en relación a la propia peana y se recorta muy próxima a los pies y al borde inferior de la vestimenta, detalles que hemos observado en un buen número de obras del imaginero.

No menos elocuente es el análisis de la cabeza del santo y sus conexiones con otras tallas de Martínez Montañés. Ese mismo gesto de introspección y humildad que vemos en los relieves citados del Bautismo ya se encuentra en el San Diego. Pero este nos remite con mayor claridad a sus Inmaculadas realizadas hacia la década de los veinte del XVII, de marcados párpados y ojos almendrados y entornados. En alguna pieza de similar expresión, como ocurre con la Santa Ana de la Iglesia del Buen Suceso de Sevilla, hecha para el

\footnotetext{
12 Varios autores, 2019a: 169-171.

13 García, 2013: 218. Varios autores, 2019: 151-154. Romero, 2019: 92-96.
} 
Convento de San Alberto entre 1632 y 1633, los rasgos faciales son asimismo muy cercanos (fig. 11). Por su parte, en el ya citado San Francisco de Santa Clara se repite con cierta literalidad el rehundimiento del entrecejo y el fruncimiento de la frente que vemos en nuestro San Diego y en otras obras montañesinas, algunas tan tardías como el San Pascual Bailón de la Parroquia de Santa María la Coronada de Medina Sidonia, de 1636 (fig. 12). Tampoco podemos, obviar, finalmente la proximidad con el modelo físico de las otras representaciones de San Diego ejecutadas por el propio maestro, para Ayamonte y Sevilla (figs. 5 y 6). Esto se observa en los angulosos perfiles del rostro, con pómulos marcados y mejillas hundidas. En el caso de la imagen de Ayamonte incluso comparte análogo modelado de las orejas. Lo mismo podemos decir del escaso volumen del cabello, peinado hacia delante mediante un dibujo ondeante de gran proximidad. Una disposición del cabello sobre la frente que tampoco está muy distante del que ostenta el referido santo de Medina.

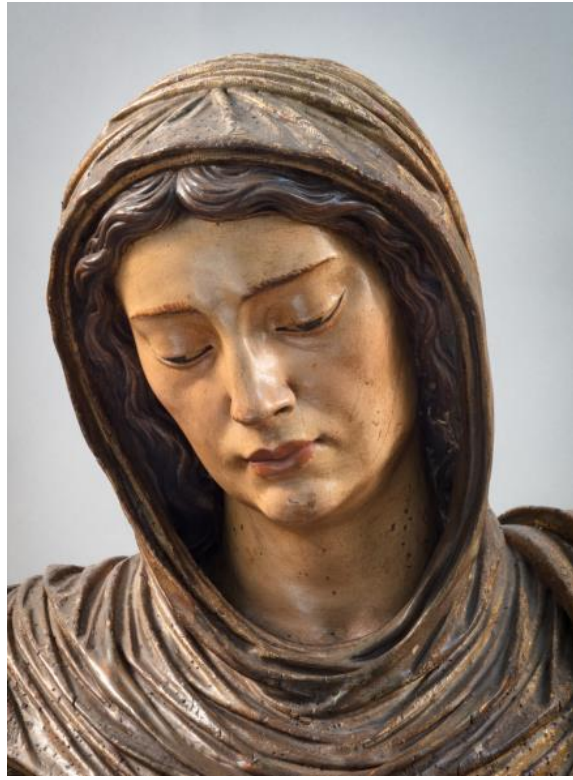

Fig. 11. Pormenor Santa Ana y la Virgen (detalle), Iglesia del Buen Suceso, Sevilla, Juan Martínez Montañés, $1632-1633$.

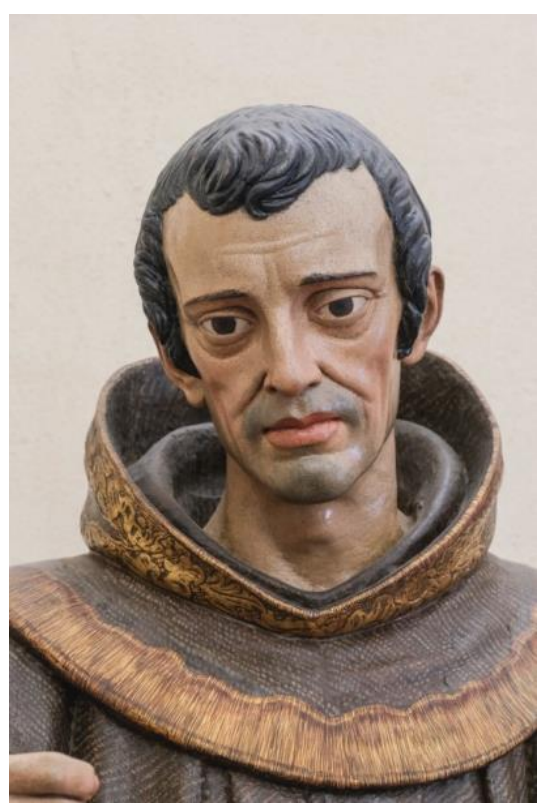

Fig.12. Pormenor San Pascual Bailón (detalle), Iglesia de Santa María la Coronada, Medina Sidonia, Juan Martínez Montañés, 1636. Autor de la fotografía: Óscar Franco Cotán.

Para acabar el análisis comparativo, merece algunas líneas el aspecto puramente técnico. Ya apuntamos al principio que la imagen está tallada en pino. A diferencia de lo que ocurre con las grandes creaciones posteriores del taller de Montañés, que hacen uso predominante de la madera de cedro ${ }^{14}$, tenemos varios testimonios del empleo del pino en la primera etapa de su producción. Es lo que se recoge en los contratos del citado San Diego encargado por Juan Sánchez en $1591^{15}$ o del célebre San Cristóbal de la Iglesia del Salvador en $1597^{16}$. Otra característica a mencionar, finalmente, es el hecho de que se encuentre ahuecada en su interior, como hemos podido comprobar personalmente. Se trata de un detalle habitual en las obras montañesinas y que ya aparece reflejado en la escritura por la que Montañés se compromete a hacer la referida escultura de San Cristóbal.

En cuanto a la cronología de la obra, el asunto reviste cierta complejidad, debido a que no tenemos fuentes documentales referidas a ella. A pesar de ello, la existencia de la talla jerezana de Lamberto, basada inequívocamente en el modelo montañesino y fechada hacia

\footnotetext{
14 Varios autores, 2019a: 108.

${ }^{15}$ López, 1932: 229.

16 López 1932: 231.
} 
1591-1592, nos lleva a proponer que la nueva pieza que atribuimos a Montañés se haría hacia 1590-1591, por lo que podría ser uno de los primeros ejemplares conservados de la producción artística del "Dios de la Madera". Esto, no sólo nos hablaría de la precocidad técnica del joven Montañés, tras haber alcanzado algo más de veinte años de edad, sino también de cierta inmutabilidad estilística. De este modo, es llamativo, por ejemplo, que, entre otros pormenores, el tratamiento del hábito, realizado a través de un profundo y pesado plegado, sea tan similar al empleado en el San Francisco de Asís del Convento de Santa Clara de Sevilla, esculpido varias décadas después, hacia 1623-1625.

Por otro lado, aunque ya sabíamos que Montañés llegaría a trabajar para Sanlúcar en 1616, bajo el patrocinio de los duques de Medina Sidonia ${ }^{17}$, queremos resaltar que la presencia en el cenobio sanluqueño de una imagen suya -en fecha tan temprana y de tal entidad artística-, podría explicarse no sólo dentro de la iniciativa común de varios conventos franciscanos del área hispalense tras la canonización de fray Diego, sino también como consecuencia de la especial vinculación al lugar que tuvo el santo, que llegó a alojarse temporalmente en el monasterio sanluqueño en sus viajes entre Canarias y la Península, como en 1449 cuando se dirigía a Roma.

Recordemos que fray Diego de San Nicolás nació en 1400 en San Nicolás del Puerto, perteneciente al Reino o provincia de Sevilla. Ingresó como hermano lego en la Orden de Frailes Menores espirituales o de la Observancia, una de las ramas de la Primera Orden de San Francisco, y tuvo un importante papel en la Evangelización de las Islas Afortunadas, siendo guardián del Convento de San Buenaventura de Betancuria y llegando a ser vicario de la Misión franciscana de Canarias. Fray Diego pasó a la posteridad como San Diego de Alcalá, tras ser canonizado por la Iglesia Católica en 1588, ya que vivió los últimos años de su vida en Alcalá de Henares, donde murió en 1463 y en cuya Iglesia Magistral -hoy Catedral- se conserva su cuerpo, que se expone cada 13 de noviembre, el día de su festividad. ${ }^{18}$

Tras la muerte de fray Diego, su figura siguió siendo objeto de veneración popular, debido a los milagros que obró en vida. Entre ellos, el más famoso quizá sea el milagro de las flores, sucedido en el convento de Alcalá, cuyo guardián había ordenado a sus hermanos que redujeran el pan que daban en la puerta, porque ellos mismos estaban pasando apuros. Así, en una ocasión, el superior se cruzó con Diego y, viendo que llevaba algo escondido en el hábito, le increpó, creyendo haberle cogido in fraganti. Pero al comprobarlo, las mangas de fray Diego resultaron estar llenas de rosas, que cayeron al suelo, aunque ni siquiera era el tiempo de su floración ${ }^{19}$.

Además de este y otros prodigios, casi un siglo después de su muerte se produjo un hecho que relanzó enormemente el culto al fraile andaluz. Nos referimos a la curación del príncipe Carlos, heredero del rey Felipe II, acontecida en 1562. Estando don Carlos retirado de la Corte en Alcalá de Henares, curándose de unas fiebres, el 19 de abril después del almuerzo cayó por una escalera oscura, hiriéndose gravemente en la cabeza. Durante su larga convalecencia, el cuerpo de fray Diego, que se conservaba en el convento franciscano de la villa, fue conducido -con la esperanza de que se obrara un milagro- a la cámara del príncipe, que contaba solo diecisiete años. El traslado de la reliquia se hizo en presencia del rey, el día 9 de mayo, quedando el heredero desahuciado por los médicos esa misma noche. Sin embargo, tras varios días don Carlos acabó recuperándose, relatando que aquella noche que agonizaba, fray Diego se le había presentado para reconfortarle, diciéndole que no temiera pues se curaría. Tras ello, el príncipe quedó agradecido de por vida, prometiendo públicamente en repetidas ocasiones que pediría la canonización del franciscano ${ }^{20}$.

Pero el malogrado heredero de Felipe II murió en 1568, a los veintitrés años de edad, y la canonización de fray Diego no se produciría hasta 1588, diez años antes de la muerte de su padre, el Rey Prudente, que fue su principal artífice. En este contexto de devoción a San

\footnotetext{
${ }^{17}$ Romero/Moreno, 2017: 193-210.

18 Case, 1998: 1-182.

${ }^{19}$ Cetina, 1609: 103-104.

${ }^{20}$ Daza, 1842: 537-563.
} 
Diego por parte de la familia real, recientemente se ha propuesto que el fraile autómata conservado en el Museo Nacional de Historia Americana, podría representar nuestro fraile marucho y ser obra del insigne ingeniero cremonés al servicio de Felipe II Juanelo Turriano ${ }^{21}$.

Pero más allá de lo especulativo, sabemos con certeza que Lope de Vega escribió en 1588 un bello soneto conmemorativo de la canonización de fray Diego. Creemos que dicho poema pudo tener impacto en la creación de la iconografía del santo por parte de Martínez Montañés, por lo que a continuación lo reproducimos parcialmente:

"La verde yedra al verde tronco asida,
trepando por sus ramas tanto crece,
que yedra el árboly ella árbol parece
enlazada en sus brazos sostenida. [...]
Asi a la cruz divina, Diego, asido,
sus brazos con los vuestros enlazados,
arribásteis por ella al alto cielo. ${ }^{22 " "}$

La lectura de estos versos de Lope nos forma la metafórica imagen del santo, que abraza la cruz de Cristo, como la hiedra que se agarra a un árbol para subir hacia lo alto. Precisamente este gesto -cercano, amoroso y firme- es el principal acierto de la nueva imagen de Montañés que presentamos. Además, las voluminosas mangas del hábito, más allá de su atractivo visual, bien podrían tener la intención de aludir al milagro de las rosas, pues en los relatos antiguos se nos dice que el santo escondió los panes dentro de sus mangas ${ }^{23}$. Comoquiera que fuera la intención del artista, la verdad es que en la imagen de Sanlúcar Montañés creó un modelo que aúna magistralmente el abrazo a la cruz y el milagro de las rosas.

En el caso del abrazo, además de las copias claramente basadas en el original, realizadas por Hernando Lamberto, queremos mencionar otras tres imágenes del santo que podrían haberse realizado bajo la influencia del prototipo. Nos referimos al San Diego que está en la Iglesia de la Antigua de Almensilla, en la Parroquial del municipio canario de San Andrés y Sauces -en la isla de La Palma-, y el ubicado en la Iglesia de San Francisco de Utrera. Son tres obras que, a pesar de su disparidad estilística y cronológica, comparten con nuestro San Diego el amoroso abrazo a la cruz, que va más allá del convencional sostenimiento de la misma, presente en la mayoría de las representaciones del fraile. Asimismo, en el ámbito de la pintura, el único artista que parece haber dado este mismo tratamiento a la iconografía del santo -aunque solo de forma anecdótica-, fue Zurbarán o, al menos, su obrador, como vemos en la pintura de busto conservada en la Galería Nacional de Irlanda y en la versión de cuerpo entero salida de su obrador, en colección particular ${ }^{24}$. En cuanto al milagro de las rosas, en el caso de que admitiéramos que las voluminosas mangas de nuestro San Diego hicieran alusión a él, su iconografía sería algo verdaderamente excepcional. De hecho, en la mayoría de las representaciones del fraile -tanto pictóricas como escultóricas- lo habitual es que el santo lleve las flores en un hueco creado en su hábito, ligeramente arremangado. De esta manera los vemos en conocidos ejemplos de Carracci, Ribera, Murillo, Gregorio Fernández, Alonso Cano o Pedro de Mena.

Pero volviendo al contexto geográfico de nuestra escultura, recordaremos que según la tradición, San Diego se alojó en Sanlúcar en una celda de retiro del Convento de San Francisco el Viejo, ocupando sus días en la meditación y al cuidado del huerto. Junto a su celda, plantó un pino cuya corteza y piñones se consideraban milagrosos y eran aplicados contra las calenturas y otros males. Así, siguiendo esa tradición piadosa, en 1719 la celda fue reedificada por la comunidad, convirtiéndola en ermita bajo la advocación del santo ${ }^{25}$.

\footnotetext{
${ }^{21}$ Varios autores, 2019b: 256-257.

${ }^{22}$ Case, 1988: 32.

${ }^{23}$ Cetina, 1609: 103-104.

${ }^{24}$ Delenda, 2010: 431.

${ }^{25}$ Velázquez-Gaztelu, 1995: 520.
} 
Finalmente, debemos decir que la existencia en Sanlúcar de esta Ermita de San Diego, edificada a principios del siglo XVIII y abandonada a mediados del XX, podría explicar que la imagen de Montañés no aparezca en los antiguos inventarios de la Iglesia de San Francisco, fechados en el siglo XIX ${ }^{26}$. Así, podemos suponer que, con la edificación de la ermita, la imagen de San Diego fue trasladada a ella desde el vecino convento. En la ermita debió permanecer hasta bien entrado el siglo XX en que el pequeño edificio quedó abandonado y en progresiva ruina. De este modo, sometida a unas condiciones de conservación negligentes, la imagen debió de quedar gravemente dañada, hasta que fue trasladada definitivamente a la iglesia del convento nuevo. Estos hipotéticos avatares explicarían el nefasto repinte contemporáneo que hoy en día presenta la imagen.

En conclusión, se trata de una obra de gran interés histórico-artístico, que proponemos con firmeza añadir al catálogo de Montañés, que podría ser uno de sus primeros trabajos conservados y que, en consecuencia, reclama una mejor ubicación y una correcta restauración.

${ }^{26}$ Cruz, 2009: 173-197. 


\section{Bibliografía}

Case, Thomas E.: Lope de Vega: San Diego de Alcalá. Edición crítica. Kassel: Edition Reichenberger. (1988).

Case, Thomas E.: La historia de San Diego de Alcalá: su vida, su canonización y su legado. Alcalá de Henares: Universidad. (1998).

Cetina, Fray Melchor de: Discursos sobre la vida y milagros del glorioso padre San Diego. Madrid: Imprenta de Luis Sánchez. (1609).

Contreras-Guerrero, A.: Escultura en Colombia. Focos productores y circulación de obras (siglos XVIXVIII). Granada: Universidad. (2019)

Cruz Isidoro, F.: "Patrimonio artístico desamortizado del convento de San Francisco "El Nuevo" de Sanlúcar de Barrameda (1821-1835)". En: Laboratorio de Arte, 21 [Núm], Sevilla, pp. 173-197. (2009).

Delenda, O.: Zurbarán. Los conjuntos y el obrador. Volumen II. París: Instituto Wildestein. (2010).

García Luque, M.: "Fuentes grabadas y modelos europeos en la escultura andaluza (16001650)". En Gila Medina, Lázaro (coordinador): La consolidación del Barroco en la escultura andaluza e hispanoamericana. Granada: Universidad, (2013), pp. 179-256.

Gila Medina, L. y Herrera García, Francisco J.: "Escultores y esculturas en el Nuevo Reino de Granada (Colombia)". En Gila Medina, Lázaro (coordinador): La escultura del primer naturalismo en Andalucía e Hispanoamérica (1580-1625). Madrid: Arco, (2010), pp. 501-562.

Hernández Díaz, J.: Estudio iconográfico y técnico de la imaginería montañesina. Sevilla: Academia de Bellas Artes de Santa Isabel de Hungría, (1939).

Hernández Díaz, J.: Juan Martinez Montañés. Sevilla: Universidad. (1949).

Hernández Díaz, J.: "Novedades en torno a Montañés". En: Varios autores: Homenaje al Profesor Cayetano de Mergelina. Murcia: Universidad, (1962), pp. 451-458.

Jácome González, J. / Antón Portillo, J.: "Aproximación a la vida y obra del entallador y escultor flamenco Hernando Lamberto en Jerez de la Frontera". En: Revista de Historia de Jerez, 9 [Núm], Jerez de la Frontera, (2003), pp. 43-74.

López Martínez, C.: Desde Martinez. Montañés hasta Pedro Roldán. Sevilla: Imprenta Rodríguez. (1932).

Mesa Xinete, F. de: Historia Sagrada y Política de la Muy Noble y Muy Leal Ciudad de [...] Jerez de la Frontera. Tomo I. Jerez de la Frontera: Imprenta de Melchor García Ruiz. (1888).

Pemán, M.: "Una obra maestra de la escultura española recuperada para el arte en Cádiz". En: Revista de Arte Sevillano, 2 [Núm], Sevilla, (1982), pp. 21-27.

Daza Chacón, D.: "Relación verdadera de la herida de cabeza del Serenísimo Príncipe D. Carlos". En: Colección de documentos inéditos para la historia de España, Volumen 18. Madrid: Imprenta de José Perales y Martínez. (1842).

Romero Dorado, A./ Moreno Arana, J. M.: "Juan Martínez Montañés y los Guzmanes: la Virgen con el Niño de la catedral de Huelva (1616)". En: BSAA Arte, 83 [Núm], Valladolid, (2017), pp. 193-210.

Romero Torres, J. L.: "Juan Martínez Montañés, Francisco de Ocampo y José de Arce: nuevas aportaciones al estudio de sus fuentes iconográficas". En: Cuadernos de los Amigos de los Museos de Osuna, 21 [Núm], Osuna, (2019), pp. 92-98.

Sancho, H.: "La reforma de la iglesia conventual de San Francisco de Cádiz (siglo XVIII)". En: Archivo Ibero-Americano, 9 [Núm], Madrid, (1949), pp. 297-298.

Velázquez-Gaztelu, J. P.: Fundaciones de todas las iglesias, conventos y ermitas de Sanlúcar de Barrameda. Año de 1758. Sanlúcar de Barrameda: ASEHA. (1995).

Varios autores: Montañés, maestro de maestros. Catálogo de la exposición celebrada en el Museo de Bellas Artes de Sevilla, del 29 de noviembre de 2019 al 15 de marzo de 2020. Editado por Ignacio Cano Rivero, Ignacio Hermoso Romero y María del Valme Muñoz Rubio. Sevilla: Junta de Andalucía, Consejería de Cultura y Patrimonio Histórico. (2019a).

Varios autores: Making marvels. Science and Splendor at the Courts of Europe. Nueva York: Metropolitan Museum of Art. (2019b). 